\title{
Flow-type failures in fine-grained soils: an important aspect in landslide hazard analysis
}

\author{
T. W. J. van Asch $^{1,2}$ and J.-P. Malet ${ }^{3}$ \\ ${ }^{1}$ Utrecht University, Faculty of Geosciences, P.O. Box 80115, 3508 TC Utrecht, The Netherlands \\ ${ }^{2}$ Delft University of Technology, Water Resources Section, Faculty of Civil Engineering and Geosciences, P.O. Box 5048, \\ 2600 GA Delft, The Netherlands \\ ${ }^{3}$ School and Observatory of Earth Sciences, Institute of Earth Physics, UMR 7516 UdS-CNRS, 5 rue Descartes, 67084 \\ Strasbourg Cedex, France
}

Received: 6 November 2008 - Revised: 11 June 2009 - Accepted: 8 September 2009 - Published: 15 October 2009

\begin{abstract}
Forecasting the possibility of flow-type failures within a slow-moving landslide mass is rarely taken into account in quantitative hazard assessments. Therefore, this paper focuses on the potential transition of sliding blocks (slumps) into flow-like processes due to the generation of excess pore water pressure in undrained conditions. The generation of excess pore water pressure may be the consequence of deformation of the landslide body during motion. Two model concepts are proposed and discussed. The first concept is the so called strain concept model where emphasis is laid on strain changes due to differential movement within the moving mass. This may create zones of compression and dilation and consequently excess pore water pressures. The second concept is the so called topographical concept model which focuses on changes in the stress field of the landslide caused by geometric changes in topography of the moving body. Both models were tested on two slumps which developed in secondary scarps of the Super-Sauze mudslide in the Barcelonnette Basin (South French Alps). The slump which developed in 1999 showed complete fluidization; all the material was removed from the source area and transformed into a mudflow. The second slump, dated from 2006, did not show fluidization; it has a relative short displacement and all the material remained in the source area. It appeared that the strain concept model predicted flow-type failure for both slumps, after relative short displacements, while the topographical concept model predicted only flow-type failure for the 1999 slump and not for the 2006 slump. The strain concept model seems too conservative in forecasting the fluidization potential of slumping blocks.
\end{abstract}

Correspondence to: J.-P. Malet (jeanphilippe.malet@eost.u-strasbg.fr)

\section{Introduction}

Although increasing attention is focused on vulnerability analysis, risk assessment and risk management in landslide research, there are still important issues related to hazard assessment. Indeed, an essential part of any hazard assessment is a quantitative estimate of the pre-failure and failure stages defining the susceptibility of the slope or of the sliding material to a dramatic acceleration or even to a flow-type failure with important run-out distances and velocities. Some slope movements are slow and ductile, other slope movements are brittle, meaning that, after a certain prelude of slow deformation or as the result of sudden loading, they accelerate and potentially fluidize (e.g. gradual deformation vs. rapid run-out). The essence of analysing landslide motion should therefore revolve around the accurate reproduction of the deceleration and acceleration of landslide bodies and, in particular a reliable forecast of the potential transformation towards catastrophic, extremely rapid surges.

The preparatory work towards failure is related to slope evolution in terms of related changes in stress field (Brunsden, 1999), of hydro-chemical and mechanical deterioration (e.g. damage), and of the development of crack systems (Boukharov et al., 1995; Kilburn and Petley, 2003; Amitrano, 2003). In the last stage of the pre-failure process, displacements can be monitored and detected but research has still to be carried out to interpret the displacement curves and the underlying propagation processes in order to forecast acceleration periods (Petley et al., 2002; Helmstetter et al., 2004). This issue is particularly important for intermittently and gradually moving landslides which can partly evolve into rapid gravitational flows. An important aspect of hazard assessment is to better understand the controlling factors and triggering processes of flow-type failure in fine-grained soils because they determine the amount of initial material which

Published by Copernicus Publications on behalf of the European Geosciences Union. 
has a major impact on the run-out distance in the track and spreading on the depositional (fan) areas.

This requires a thorough understanding of the factors controlling landslide motion. The parameterization of hydrological and geomechanical factors by field and laboratory tests is not always sufficient to describe the movement patterns of these landslides (van Asch et al., 2006). The variations in the hydro-mechanical properties over time and space and factors operating at the field scale like geometrical effects (Nieuwenhuis, 1991), deformation effects (Giusti et al., 1996; Picarelli et al., 2005) and hydro-mechanical feed back mechanisms (Keefer and Johnson, 1983; van Genuchten, 1989; Picarelli et al., 1995; Angeli et al., 1996) have to be considered.

The focus of this paper is the analysis of the conditions of flow-type failures of sliding material in soils. There are several mechanisms which may generate fluidization in loosely packed or dense soils (Ishihara, 1993), such as:

- the contraction of coarse-grained, loosely-packed saturated soils during shearing (Harp et al., 1990; Anderson and Riemer, 1995; Iverson et al., 1997; Dai et al., 1999; Eckersley, 2000; Chu et al., 2003; Wang and Sassa, 2003);

- undrained loading of fine-grained, more densely packed soils, caused by a changing stress field during initial failure and the development of excess pore water pressures because of alternate zones of compression and dilatation controlled by changes in slope gradient along the slip surface (Baum and Fleming, 1991; Picarelli et al., 1995; Giusti et al., 1996; Klubertanz et al., 2000; Comegna and Picarelli, 2005; van Asch et al., 2006);

- the progressive decrease in inter-granular stresses caused by the rotation of the seepage force vector of the groundwater flow in a direction opposite to gravity (Iverson et al., 1997);

- the reduction of the soil porosity (e.g. void ratio) caused by shearing breaks of the soil particles near the slip surface (Sassa, 1998; Iverson et al., 2000).

In the literature, less attention was given to the role of landslide geometry and kinematics in the possible fluidization of the sliding material (van Asch et al., 2006). The aim of this paper is to analyse two concepts of flow-type failure controlled by geometry and kinematic deformation of a landslide body. Simple numerical models are tested on two slump-type failures that occurred on the Super-Sauze mudslide in the Barcelonnette Basin (Southeast France). The first slump exhibits a flow-type pattern while the second slump did not show any sign of fluidization. The Super-Sauze mudslide is characterized by its capability to suddenly change behaviour, and transform into muddy debris flows. Due to their sediment volume, and their high mobility, debris-flows induced by such landslide types are very dangerous. For hazard assessment, it is therefore important to understand why
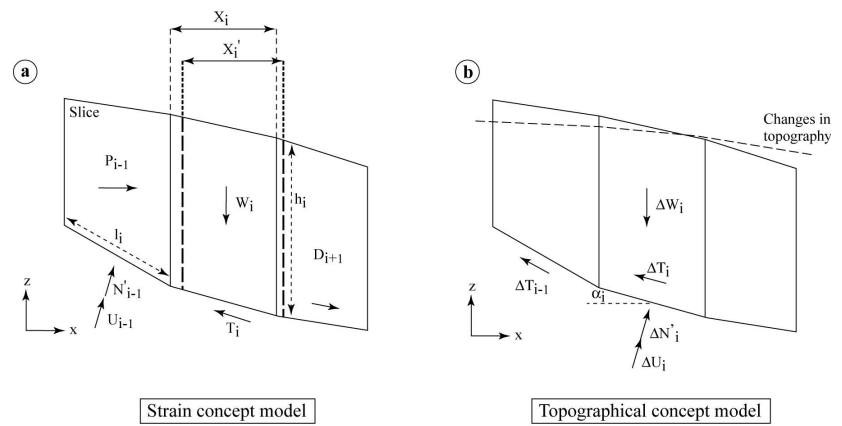

Fig. 1. Two main causes which may generate flow-type failures of fine-grained landslides: (a) Deformation of the slices due to differential displacements $S: \varepsilon_{x x}=\left(X_{i}-X_{i}^{\prime}\right) / X_{i}$. Description of the forces is detailed in the text. (b) Geometric changes of the topography and consequent changes in the mobilized Coulomb shear strength forces $T$ and normal forces $N^{\prime}$ calculated according to the Bishop equilibrium model.

and how some of these mudslides transform into debris-flows while most of them stabilize and to analyze their hydrological and geomechanical behaviour, which determine the runout characteristics (Malet et al., 2005).

\section{Two concepts of flow-type failure caused by sliding displacements}

\subsection{General description of the concepts}

Two concepts have been developed to describe the conditions for flow-type failures caused by sliding displacement. The first concept is focussing on the strain process during movement, which means a change in volume of the material and hence a change in stress generating excess pore water pressure. It is called the strain concept model (Fig. 1a). The second concept is focused on the change of the stress field in each slice, caused by the topographical concept without considering strain or volume change of the moving material generating excess pore water pressure by undrained loading. It is called the topographical concept model (Fig. 1b).

\subsection{Calculation of the displacement and velocity}

In both concepts, the Bishop equation of limiting equilibrium (Bishop, 1955) is used to analyse the role of different portions of a landslide body, by dividing the area above the slip surface into slices of a constant width. The landslide body is therefore divided in our case in i slices of which Fig. 1 shows three slices: $i-1, i$ and $i+1$. The forces which are considered in these slices are given a suffix referring to the number of the slice. For example, $P_{i-1}$ refers to slice $i-1$. In Fig. 1, not all the forces and geometric information are depicted in the same slice for reason of clarity. They are spread over the three slices and give together complete information of what 
is needed for the analysis of one slice. They are used to calculate the balance of forces per slice in order to calculate the displacement of individual slices and the mass propagation down slope. The Bishop equation is used to resolve the forces per slice and to integrate these forces over the total number of slices to calculate the overall safety factor at the start of the movement. Pore water pressure conditions at the start are adjusted in order that instability occurs in the rigid block for an overall safety factor which is chosen arbitrarily at a value lower than the unity. Due to the unstable conditions, which are initially created, displacement can start. After failure it is assumed that a thin viscous slip surface of thickness $\mathrm{m}$ and viscosity $\mu$ develops. The imposed instability creates excess shear stresses that are converted through viscosity into displacement. During the movement there is equilibrium between the driving force $(D)$, the pressure force $(P)$, the resisting force $(T)$ and the viscous resistance component $(\eta)$, for each slice $i$. It is assumed that the inertial term due to acceleration can be neglected (Fig. 1). Therefore, the mass balance can be written using Eq. (1):

$D_{i}^{t}+P_{i}^{t}-T_{i}^{t}-v \frac{\eta}{m} l_{i}=0$

where the subscript $i$ refers to slice number $i$ and the superscript $t$ to time step $t$. In the equations, the subscript $i-1$, $i, i+1$ referring to slice numbers and the super scripts $t-1$, $t, t+1$ referring to the time steps will be used only in case more than one slice number or time step are considered in the equation. In case subscripts and superscripts are omitted, we are referring to slice $i$ and time step $t$. In Eq. (1), $l_{i}$ is the length of the slip surface of slice $i$ (Fig. 1a), $m$ is the thickness of the viscous shear zone and $\eta$ is the viscosity of the shear zone. Since $m$ is not known most of the time the ratio $v / m$ is taken as a lumped parameter in the calibration.

The force in (Eq. 1) is defined by the tangential component of the weight for a given slice (Eq. 2):

$D=W \sin \alpha$

where $\alpha$ is the angle of the slip surface of the slice.

The pressure term $P$ in Eq. (1) at the start of movement is derived from the horizontal inter-slice net force, which can be solved for each slice according to Bishop's limit equilibrium equation. The resistance term $T$ in Eq. (1) is given by Eqs. (3-4) according to Bishop (1955).

$$
\begin{aligned}
& T=c l+(N-U) \tan \phi \\
& N=\left[W-\frac{1}{F} \sin \alpha(c l-U \tan \phi)\right] / m_{\alpha} \\
& m_{\alpha}=\cos \alpha\left(1+\tan \alpha \frac{\tan \phi}{F}\right)
\end{aligned}
$$

where $c$ and $\phi$ are respectively cohesion and friction angle of the material, $U$ is the pore water pressure (Fig. 1) and $F$ is the overall safety factor which is set arbitrarily at a value lower than the unity.
The velocity $\mathrm{v}$ of a given slice $\mathrm{i}$ can be calculated by rewriting Eq. (1) into Eq. (5):

$v=\frac{m}{\eta}\left(\frac{D+P-T}{l}\right)$

The displacement $S$ during a time step $\Delta t$ for a given slice $i$ is given by Eq. (6):

$S=v \Delta t$

The new volume in the next time step in slice $i$ after movement during time step $\Delta t$ is given by Eq. (7) in which volume change by strain is ignored:

$V_{i}^{t+1}=S_{i-1}^{t} h_{i-1}^{t}-S_{i}^{t} h_{i}^{t}$

where $h_{i}$ is the height of slice $i$ at the down slope side of slice $i$ (Fig. 1).

Knowing the new volume $V_{i}^{t+1}$ of each slide, the new height $h_{i}^{t+1}$ of each slice can be calculated by assuming that $h_{0}=0$, which is at the upper boundary of the landslide.

Equations (5-7) are fundamental to calculate the propagation of the mass of the individual slices down slope at each time step, until the slices stop when the criteria $T>D+P$ in Eq. (5) is true, and hence the velocity becomes negative.

\subsection{Equations used in the strain concept modelt}

In the strain concept model, generation of excess pore water pressure due to volume change of the mass during movement is assumed. The most important dominant strain component is the normal strain in the horizontal axis $x\left(\varepsilon_{x x}\right)(-)$, which can be calculated for slice $i$ at time step $t$ by Eq. (8):

$\varepsilon_{x x}=-\frac{\left(S_{i+1} \cos \alpha_{i+1}-S_{i} \cos \alpha_{i}\right)+\left(S_{i} \cos \alpha_{i}-S_{i-1} \cos \alpha_{i-1}\right)}{l_{i} \cos \alpha_{i}}$

Equation (8) follows the definition that compressive strain is positive $\left(\varepsilon_{x x}>0\right)$ and is related to a positive stress, while a dilative strain is negative $\left(\varepsilon_{x x}<0\right)$ and is related to a negative stress.

By ignoring shear strain during movement and changes in total stress $\sigma_{z z}$ in the z-axis, van Asch et al. (2006) proposed the simplified Eq. (9) relating the minor principal stress change $\Delta \sigma_{x}$ to the minor principal strain $\varepsilon_{x}$ assuming that $\varepsilon_{x x} \approx \varepsilon_{x}$ :

$\Delta \sigma_{x}=\varepsilon_{x} E$

where $E$ is the Young's modulus of a nearly undrained material.

In case of quasi-undrained loading conditions, a saturated material and no shear strain (van Asch et al., 2006), the variation in pore water pressure $\Delta u_{\text {ini }}$ at the beginning of the time step can be described by Skempton's law (Smith and Smith, 1998) which in the case of $\Delta \sigma_{x}=0$ reduces to Eq. (10):

$\Delta u_{\text {ini }}=(1+A) \Delta \sigma_{x}=(1+A) \varepsilon_{x} E$

where $A(-)$ is Skempton's pore pressure coefficient. 
During a time step, dissipation of pore water pressure can occur. An average fractional loss $(F r)$ of the excess pore water pressure during a time step can be obtained using Terzaghi's theory of consolidation for a half closed layer, assuming an impermeable slip surface, vertical drainage upwards and one-dimensional consolidation (Whitlow, 1995) by Eq. (11):

$$
\begin{aligned}
F r= & 1-\frac{16}{\pi^{3}}\left[(\pi-2) e^{-\left(\pi^{2} / 4\right) T v}\right. \\
& +\frac{1}{27}(3 \pi-2) e^{-\left(9 \pi^{2} / 4\right) T v} \\
& \left.+\frac{1}{125}(5 \pi-2) e^{-\left(25 \pi^{2} / 4\right) T v}+\ldots\right]
\end{aligned}
$$

where $T_{v}$ is the dimensionless time factor of the consolidation and pore water dissipation process. $F r$ must have a value between 0 and 1 ; a value of 1 indicates a complete dissipation of excess pore water pressure. $T_{v}$ is defined by Eq. (11):

$T v=\frac{C_{v} t}{d^{2}}$

where $t$ is time; $d$ is the length of the drainage path which for a half-closed layer equals to the thickness of the water layer, $C_{v}$ is the coefficient of consolidation which is linearly related to the hydraulic conductivity of the material. The final value of excess pore water pressure $\Delta U_{\text {final }}$ at the end of the time step after consolidation is calculated with Eq. (12):

$$
\Delta U_{i}^{\mathrm{final}}=\left(\Delta u_{i}^{\mathrm{ini}}-\operatorname{Fr} \Delta u_{i}^{\mathrm{ini}}\right) l_{i}
$$

and is used to calculate the new value of pore water pressure $U$ in the next time step Eq. (13):

$U_{i}^{t+1}=U_{i}^{t}+\Delta U_{i}^{\mathrm{final}, t}$

The pore water pressure $U$ can be expressed as a pore pressure ratio $r_{u}$ for slice $i$ and at time $t$ by Eq. (14):

$r_{u}=\frac{U}{W}$

The variation in the value of the total lateral stress term $\Delta P_{i}$ during displacement is given by Eqs. (9) and (16):

$\Delta P=\Delta \sigma_{x} \cos \alpha h$

and is used in Eq. (17) to calculate the pressure term $P_{i}$ in the next time step:

$P_{i}^{t+1}=P_{i}^{t}+\Delta P_{i}^{t}$

\subsection{Equations used in the topographical concept model}

The topographical concept model is an adaptation of the strain concept model in which excess pore water pressure increases more slowly with displacement. The topographical concept model is developed where no deformation of the landslide body caused by differential movement is observed, and considers only changes in the stress field caused by changes in the topographical geometry of the landslide body (Fig. 1b). Using Bishop's equation, the driving force $D$ and the maximum mobilized shear strength $T$ are calculated by Eqs. (2-3). Equation (5) is used to calculate the velocity and route the slump mass in time assuming a Coulombviscous material, and Eq. (7) is used to calculate the geometrical changes of the mass in terms of new volume $V$ and new weight $W$ for each slice.

The change in geometry in this concept results in a change for each slice of the mobilized shear strength $\Delta T$ and the normal effective force $\Delta N^{\prime}$ between two time steps as indicated by Eqs. (3-4). This change in geometry can be expressed in terms of stresses by Eq. (18):

$$
\begin{aligned}
& \Delta \sigma_{z z}^{\prime}=\Delta N^{\prime} / l \\
& \Delta \sigma_{z x}=\Delta T / l
\end{aligned}
$$

Equation (19) converts $\Delta \sigma_{z z}$ and $\Delta \sigma_{z x}$ (working as respectively normal stress and shear stress at the slip plane) in changes of principal stresses $\Delta \sigma_{x}$ and $\Delta \sigma_{z}$ (Whitlow, 1995).

$$
\begin{aligned}
& \Delta \sigma_{z}=\Delta \sigma_{z x} \sin (45+\phi / 2)+\Delta \sigma_{z z} \sin (45-\phi / 2) \\
& \Delta \sigma_{x}=\Delta \sigma_{z x} \cos (45+\phi / 2)-\Delta \sigma_{z z} \cos (45-\phi / 2)
\end{aligned}
$$

Equation (20) gives the change in pore water pressure as a function of the principal stresses $\sigma_{z}$ and $\sigma_{x}$ for saturated soil according to Skempton's law (Whitlow, 1995):

$\Delta u=\Delta \sigma_{x}+A\left(\Delta \sigma_{z}-\Delta \sigma_{x}\right)$

where $A$ is a material constant.

Dissipation of pore water pressure in each time step is again calculated according to Terzaghi's theory of consolidation, as discussed in Sect. 2.3.

\section{Test of the flow-type failure concepts on field data}

\subsection{Geomorphological and geotechnical characteristics of the slumps}

Two flow-type failures, which developed in secondary scarps on the upper part of the Super-Sauze mudslide in 1999 and 2006, enabled us to test the performance of the models. The clay-rich Super-Sauze mudslide is characterized by a complex style of activity associating continuous slow movement ( 0.002 to $0.03 \mathrm{~m} \mathrm{day}^{-1}$ ) of the body caused by internal creep in relation to seasonal changes in pore water pressures, and acceleration in relation to local lateral compression of the material during motion, undrained loading and the development of excess pore water pressures. These accelerations have triggered muddy debris flows, as was for instance observed in 1999, 2000, 2006 and 2008. Malet (2003) and Malet et al. (2005) have stressed that these debris flows, triggered in an impermeable stiff clay material, occurred through a combination of heavy and sustained rainfalls, thawing soils and snowmelt. Figure 2 indicates the source area of these muddy debris flows, and the location of the cross-sections of Fig. 3 for the failures of 1999 and 2006. 


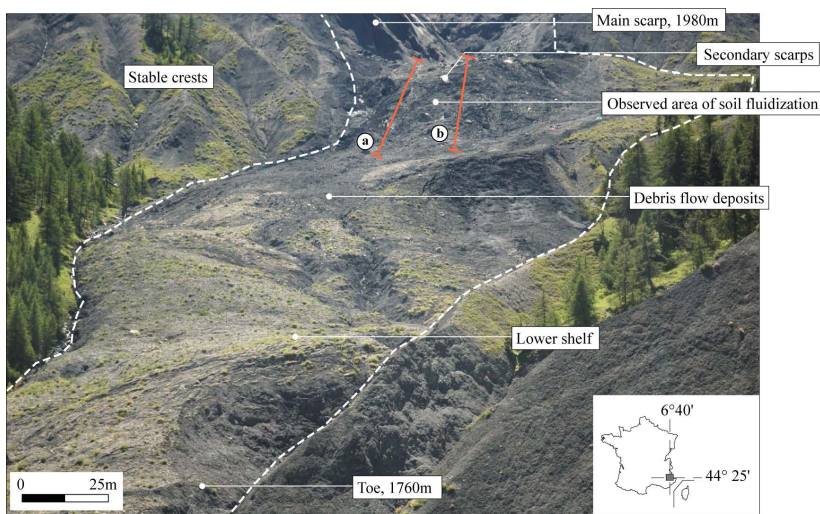

Fig. 2. Geomorphologic features of the Super-Sauze mudslide in the Barcelonnette area (France) in July 2008. Evidences of muddy debris flows deposits are clearly recognizable in the middle part of the mudslide in dark grey color, and correspond to debris flow events that occurred in May 2008. The red lines indicate the location of the cross-sections of Fig. 3.

The first failure occurred on 5 May 1999 and completely fluidized into a muddy debris flow (Figs. 3a and 4a) with a run-out distance of about $120 \mathrm{~m}$. The mean gradient of the slip surface of the slump is estimated at ca. 46 degrees. The volume of the slump has been estimated at $2500 \mathrm{~m}^{3}$. The second failure occurred on 25 October 2006 (Fig. 3b). The mean gradient of the slip surface is estimated at ca. 28 degrees. The surface displacement and the variation in pore water pressure at the toe of the slump have been monitored by an extensometer and a Casagrande-type piezometer (Fig. 4b). Figures 3b and $4 \mathrm{~b}$ show that the slumped material remained for a large part in the source area and practical no flow-type behaviour was observed after failure.

Figure 5 gives more details about the failure process of 2006. The main displacement took place in the period 25 October 2006-12 November 2006, which is around 18 days (Fig. 5). The displacement measured in point A during that period was about $5 \mathrm{~m}$ (Fig. 5). The groundwater level during this failure period varied between $-1.25 \mathrm{~m}$ and $-0.75 \mathrm{~m}$ below the topographical surface (Fig. 5). For the modeling exercise, the groundwater was kept at a level of $-0.75 \mathrm{~m}$ to create a worst case scenario creating the maximum pore water pressure induced by rain during the failure process.

\subsection{Application of the concepts to the 1999 failure}

The strain and the topographical concept models were applied on the dataset available for the two failures in order to test their performance to forecast fluidization. Table 1 indicates the value of hydrological and geomechanical parameters used in the modeling exercise.

Figure 6 shows the development of pore water pressure during the 1999 failure calculated with the strain concept model. Pore water pressure for each slice is expressed in
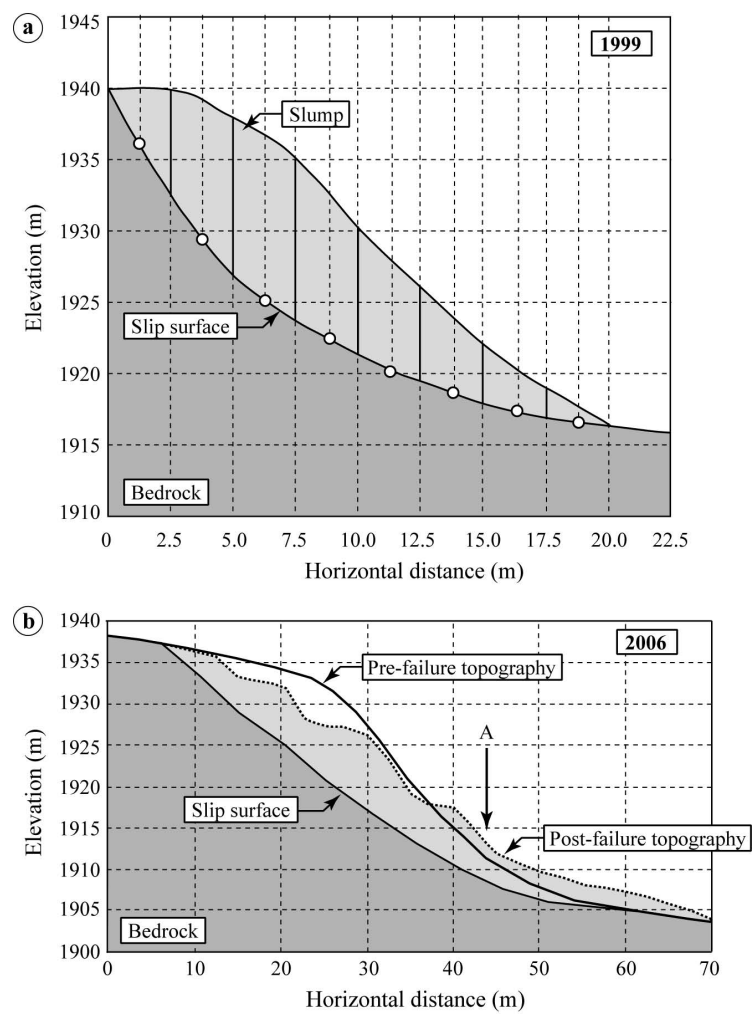

Fig. 3. Schematic cross-section of the flow-type failure of 5 May 1999 (a) where all the soil material disappeared from the source area and was transformed into a mudflow, and of 25 October 2006 (b) where a pre-failure and a post-failure topography has been reconstructed from a dGPS survey. Note the difference in the horizontal scale between Fig. 3a and $b$.

this figure and subsequent figures in terms of a pore pressure ratio as indicated in Eq. (15). When $r_{u}=1$, the effective stress between the grains is zero and the material is in a state of fluidization

Figure 6 shows the successive fluidization of parts of the slump from the toe upwards in relation to the mean displacement of the slump. Once a displacement of $0.07 \mathrm{~m}$ is reached, two slices between 17.5 and $20.0 \mathrm{~m}$ measured from the main scarp, have reached a pore water pressure value of 1 and are fluidized (Fig. 6). The figure shows that three slices between 10 and $15 \mathrm{~m}$ fluidized after a displacement of respectively $0.09 \mathrm{~m}, 0.14 \mathrm{~m}$ and $0.48 \mathrm{~m}$. After a further displacement to $1.3 \mathrm{~m}$, the overall safety factor increase to a value of $F_{s}=1.1$ and the landslide is assumed to stop (Table 2). Incidentally, the upper part of the slump exhibits a decrease in pore water pressure due to dilatation. Consequently, the pore water pressure has been arbitrarily set at a minimum of zero as the generation of very negative suction is hypothetical due to the development of cracks in this dilative section.

The strain concept model is not able to explain the total fluidization of the slump, as observed in the field (van Asch et al., 2006). The simulations indicate that about half of the 
Table 1. Geotechnical and hydrological characteristics of Terres Noires mudslide materials used for modeling the failures observed at Super-Sauze in 1999 and 2006.

\begin{tabular}{lll}
\hline Parameter [unit] & Value & Source \\
\hline Cohesion, $c[\mathrm{kPa}]$ & 14 & Laboratory $^{1}$ \\
Friction angle, $\left.\phi{ }^{\circ}\right]$ & 32 & Laboratory $^{1}$ \\
Saturated hydraulic conductivity, $K_{\mathrm{sat}}\left[\mathrm{m} \mathrm{s}^{-1}\right]$ & $1.410^{-6}$ & Laboratory $^{1}$ \\
Young's elastic modulus $[\mathrm{kPa}]$ & $3.210^{4}$ & Literature \\
Consolidation coefficient, $C_{v}\left[\mathrm{~m}^{2} \mathrm{~s}^{-1}\right]$ & $6.3610^{-7}$ & Literature/Laboratory ${ }^{1}$ \\
Skempton's pore water pressure coefficient, $A[-]$ & 0.5 & Literature \\
Dynamic viscosity, $\eta[\mathrm{kPa}]$ & 1999 failure: $1.2110^{+3}, 2006$ failure: $7.4110^{+6}$ & Calibration \\
\hline
\end{tabular}

1 Values obtained from Malet (2003) and Maquaire et al. (2003).

Table 2. Comparison between observed and modeled displacements and fluidization potential for the 1999 and 2006 failures of the Super Sauze mudslide.

\begin{tabular}{|c|c|c|c|c|c|c|c|}
\hline \multirow[t]{2}{*}{ Slump } & \multirow[t]{2}{*}{ Model concept } & \multicolumn{2}{|c|}{ Displacement before the onset of fluidization [m] } & \multicolumn{2}{|c|}{ Total volume fluidized [\%] } & \multicolumn{2}{|c|}{ Total displacement [m] } \\
\hline & & Observed & Modeled & Observed & Modeled & Observed & Modeled \\
\hline \multirow[t]{2}{*}{1999} & Strain & No data & $0.07 \mathrm{~m}$ & $100 \%$ & $52 \%$ & $120 \mathrm{~m}$ & $1.3 \mathrm{~m}$ \\
\hline & Topographical & No data & $1.16 \mathrm{~m}$ & $100 \%$ & $44 \%$ & $120 \mathrm{~m}$ & $3.1 \mathrm{~m}$ \\
\hline \multirow[t]{2}{*}{2006} & Strain & No fluid. & $0.43 \mathrm{~m}$ & $0 \%$ & $48 \%$ & $5.2 \mathrm{~m}$ & $3.2 \mathrm{~m}$ \\
\hline & Topographical & No fluid. & No fluid. & $0 \%$ & $0 \%$ & $5.2 \mathrm{~m}$ & $5.1 \mathrm{~m}$ \\
\hline
\end{tabular}
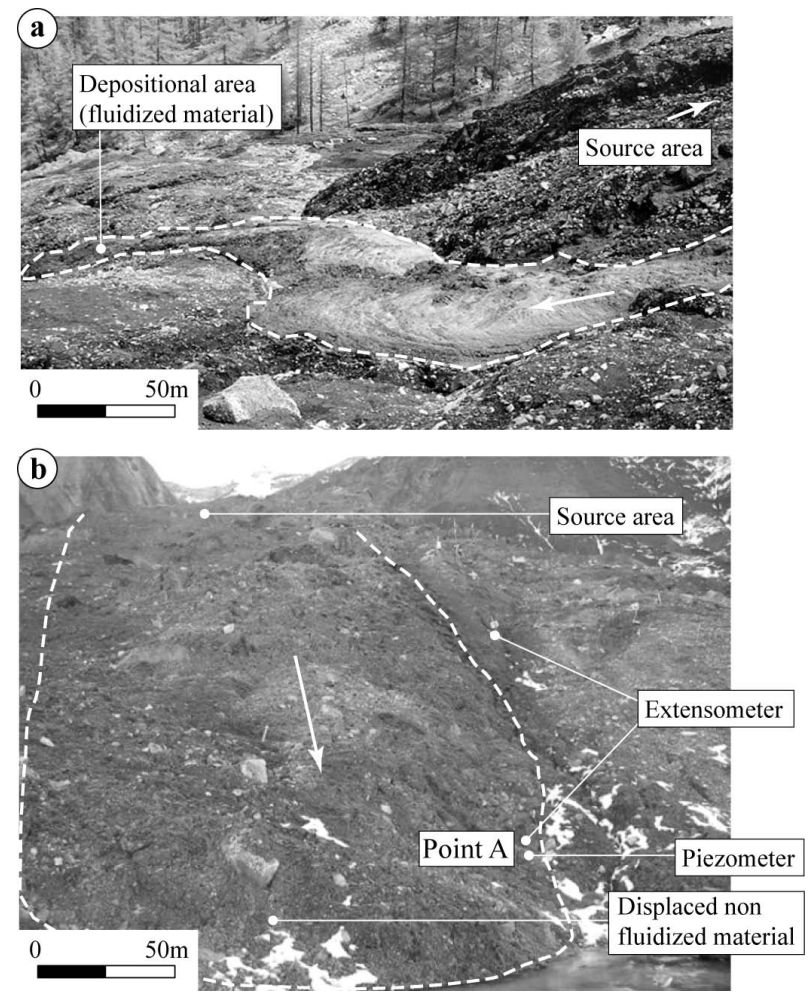

Fig. 4. Geomorphologic features of the 1999 failure (a, side view on the depositional area) and 2006 failure (b, face view on the source and depositional areas).

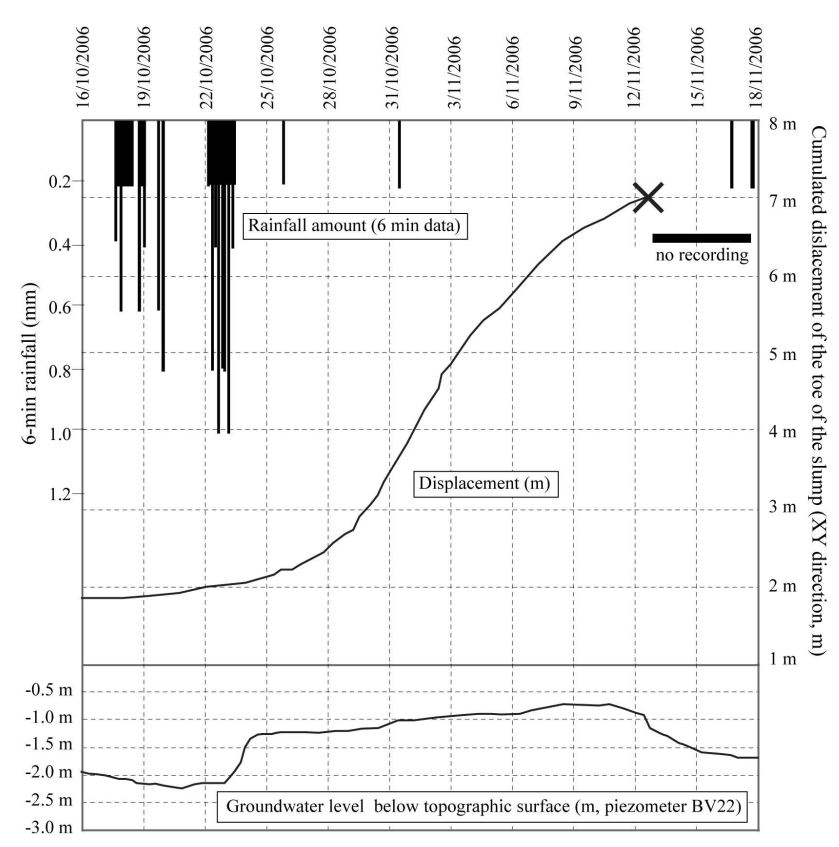

Fig. 5. Groundwater level and displacement dataset monitored at the toe of the 2006 failure (Point A, Figs. 3b and 4b) during the failure period 25 October 2006-12 November 2006. 


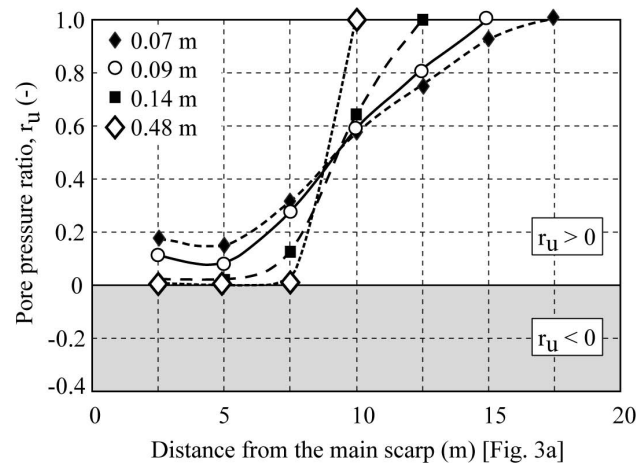

Fig. 6. Development of pore water pressure for the individual slices (indicated by the point symbols) of the 1999 failure in relation to the mean displacement of the slump. A pore pressure ratio of $r_{u}=1$ indicates fluidization of the slice.

slumping mass fluidized, while observation showed a nearly $100 \%$ fluidization (Malet et al., 2005). The stabilization of the remaining part of the slump is certainly not correctly simulated because of the calculated decrease in pore water pressure towards zero in the upper part of the dilating slump which adds strength to the soil and hence stability.

The application of the topographical concept model on the 1999 slump gives more or less the same result with respect to the amount of fluidized volume, but the predicted displacements are larger $(1.16 \mathrm{~m})$ before fluidization can start (Table 2).

\subsection{Application of the concepts to the 2006 failure}

Application of the topographical concept model to the 2006 failure is detailed on Fig. 7. Figure 7a shows the reconstruction of the maximum level of the phreatic surface based on groundwater levels observations at $42.5 \mathrm{~m}$ distance from the crown in piezometer BV22 (Figs. 3b and $4 \mathrm{~b}$ ) and previous observations of maximum groundwater levels at $15 \mathrm{~m}$ distance from the crown (Malet et al., 2005). Between these two points, the position of the phreatic surface has been calibrated to obtain a safety factor at the start of the simulation of $F_{s}=0.98$. In that case, the slope is unstable enough to reach a displacement of $5 \mathrm{~m}$ before stoppage, which is in accordance to the observed displacements monitored on the site with an extensometer (Fig. 5). A comparison of the observed and simulated post-failure topography (Fig. 7a) shows some irregularities in the measured profile with minor scarps and counter scarps. This may be ascribed to a more irregular slip surface than the simple one used in the simulation. The simulated profile indicates also a thicker material accumulation at the toe.

The dynamic viscosity parameter has been calibrated on the run-out duration of a minimum of 18 days (Table 1; Fig. 5). Figure $7 \mathrm{~b}$ shows the distribution of pore water pressure after displacement of respectively $3.06 \mathrm{~m}, 4.03 \mathrm{~m}$, $4.67 \mathrm{~m}$ and $5.05 \mathrm{~m}$ calculated with the topographical con-
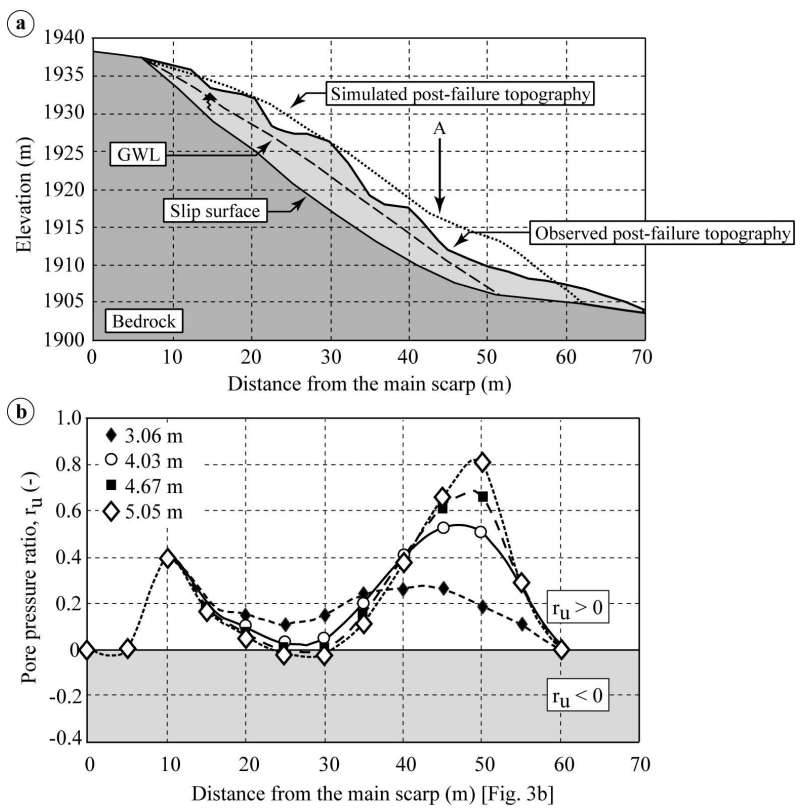

Fig. 7. Numerical analysis of the 2006 failure with the topographical concept model. (a) Simulated groundwater levels and postfailure topography. (b) development of pore water pressures for the individual slices (indicated by the point symbols) of the 2006 failure in relation to the mean displacement of the slump. A pore pressure ratio of $r_{u}=1$ indicates fluidization of the slice. GWL is the position of the ground water level within the slump.

cept model. The slump stopped after $5.1 \mathrm{~m}$ and no fluidization could be simulated. However pore water pressures rise pretty high at the toe, which may explain some weakening and larger run-out distances than modeled (Fig. 3).

The application of the topographical model concept indicates a slight onset to fluidization in the lower part of the slump after a displacement of $0.43 \mathrm{~m}$. However according to the strain concept model, $48 \%$ of the material has been fluidized before the landslide stops (after a displacement of $3.2 \mathrm{~m}$, see Table 2). It seems that the strain concept model gives a too conservative prediction of the fluidization potential of these slumps.

\subsection{Sensitivity analyses}

Given the natural variation of the input parameter values like friction angle, cohesion, consolidation coefficient and elasticity modulus (Table 1), one can ask whether the variation of input parameters might affect the fluidization potential of the failures investigated with the two concepts. The models indicate that an increase of $50 \%$ of the strength values (cohesion, friction angle) will stabilize the landslide and no movement took place. A decrease of the strength parameters of $50 \%$ shows larger displacements before stabilization but in all cases the same amounts of fluidization was predicted as given in Table 2 . 
Table 3. Effect of the consolidation coefficient $\left(C_{v}\right)$ and elasticity modulus $(E)$ on the fluidization potential for the 1999 and 2006 failures at the Super Sauze mudslide.

\begin{tabular}{|c|c|c|c|c|c|c|c|c|}
\hline \multirow[t]{2}{*}{ Slump } & \multirow[t]{2}{*}{ Model concept } & \multicolumn{3}{|c|}{$\%$ fluidization by $\%$ change in $C_{v}$} & \multicolumn{3}{|c|}{$\%$ fluidization by $\%$ change in $E$} & \multirow{2}{*}{$\begin{array}{r}\text { Total volume } \\
\text { Observed }\end{array}$} \\
\hline & & $+50 \%$ & $0 \%$ & $-50 \%$ & $+50 \%$ & $0 \%$ & $-50 \%$ & \\
\hline \multirow[t]{2}{*}{1999} & Strain & $52 \%$ & $52 \%$ & $52 \%$ & $52 \%$ & $52 \%$ & $52 \%$ & \multirow{2}{*}{$100 \%$} \\
\hline & Topograpical & $44 \%$ & $44 \%$ & $44 \%$ & & & & \\
\hline \multirow[t]{2}{*}{2006} & Strain & $48 \%$ & $48 \%$ & $48 \%$ & $48 \%$ & $48 \%$ & $23 \%$ & \multirow[t]{2}{*}{$0 \%$} \\
\hline & Topographical & $0 \%$ & $0 \%$ & $0 \%$ & & & & \\
\hline
\end{tabular}

A $50 \%$ increase of the consolidation coefficient $\left(C_{v}\right)$ (Table 3) shows the same fluidization potential for the different scenarios (Table 2) but for larger displacements. A 50\% lower $C_{v}$ value (less dissipation capacity) shows however no higher fluidization figures. An increase in the elasticity modulus of 50\% shows for the strain concept model (not applicable for the topographical concept model) the same amount of fluidization in all cases but after much shorter displacements. A decrease in the elasticity modulus of 50\% shows after larger displacements for the 1999 failure no change in the total amount of fluidization. However for the 2006 failure, smaller fluidization amounts are calculated (Table 3) than indicated in Table 2.

\section{Discussion and conclusion}

The forecast of dangerous flow-like failures within slowmoving landslides (coarse-grained or fine-grained) is an important aspect of landslide hazard assessment. This type of failures has been observed several times at the Super-Sauze mudslide. In this type of mudslide, characterized by dense and very low permeable clay-silt matrix, not all failures are able to fluidize. The slump-type failure observed in 2006 is an example of a non flow-type failure, which has developed more slowly on a flatter slip surface.

Two concepts of flow-type failure are proposed. The first concept model is called strain model and focuses on differential displacement fields in a moving body creating, respectively, compaction and dilatation zones and generating, respectively, excess positive and negative pore water pressures. The second concept is called topographical model and describes changes in the stress field of the landslide body caused by geometric changes of the topographical surface during displacement. The test of the models indicates that the strain model is the most conservative in the sense that it forecasts flow-type failure for relative short displacements. The strain model forecasts fluidized material for both slumps, while the topographical model showed only fluidization for the 1999 failure and not for the 2006 failure.

A sensitivity analysis on the the consolidation coefficient $\left(\mathrm{C}_{v}\right)$ and elasticity modulus $(E)$ shows no great influence in the outcome of the results as can be concluded by comparing Tables 2 and 3. This is caused by the fact that in our model the geometry of the slip surface and the topographical change are the dominant factors which determine the total amount of fluidized material. A change in $C_{v}$ or $E$ will be compensated in most cases by a change of the displacement before fluidization takes place. However it is important to consider also the rate of failure because that has a great effect on the amount of dissipation $\left(\mathrm{C}_{v}\right)$ during the moving period and hence on the fluidization potential.

The total volume of fluidized material is not predicted by the models. An assumption is that the decrease of pore water pressure in the dilative zones is not correctly simulated by the model. These calculated pore water pressure values may be too low causing the remaining material to stop too early and therefore the model underestimates the volume of fluidized material. In the case of the 1999 failure, decrease in pore water pressure may not have occurred in the field due to the formation of tension cracks. Other processes may have plaid also a role in generating flow-type failures, like the infill of melt water in tensile fissures in the dilatation zone in the upper part of this slump. This may have caused the total mobilization and fluidization of the sliding material as was observed.

The question arises whether in case of partly saturated material (lower initial groundwater tables) fluidization is possible. In that case, fluidization of the saturated material is still possible but pore water dissipation is also faster due to the relative lower water table. Partly saturated slumps may flow away with on top more rigid unsaturated material. In our case for both events the groundwater table was nearly at the topographical surface.

One can ask whether lateral spreading has an effect on the fluidization process and the potential for run-out of the fluidized material. In our concept, fluidization induced by internal deformation or topographical loading, has occurred already before spreading can take place. The spreading means a thinning of the mass, which may increase the pore pressure dissipation rate and may therefore influence the run-out process.

Acknowledgements. This research was supported by the European Community in the framework of the Marie Curie Research and Training Network "MOUNTAIN-RISKS", by Agence Nationale de la Recherche (ANR) within the framework of the ECCO "ECOUPREF" Project and of the CATTEL "TRIGGERLAND" Project. 
We thank Olivier Maquaire and Robert Davidson for participating in the field measurements and for the completion of the monitoring dataset.

Edited by: A. Günther

Reviewed by: two anonymous referees

\section{References}

Amitrano, D.: Brittle-ductile transition and associated seismicity: experimental and numerical studies and relationship with the $b$ value, J. Geophys. Res., 108(B1), 2044, doi:10.1029/2001JB000680, 2003.

Anderson, S. A. and Riemer, M. F.: Collapse of saturated soil due to reduction in confinement, J. Geotech. Eng.-ASCE, 121(2), 216220, 1995 .

Angeli, M. G., Gasparetto, P., Menotti, R. M., Pasuto, A., and Silvano, S.: A visco-plastic model for slope analysis applied to a mudslide in Cortina d'Ampezzo, Italy, Q. J. Eng. Geol., 29, 233 240, 1996

Baum, R. and Fleming, R. W.: Use of longitudinal strain in identifying driving and resisting elements in landslides, Geol. Soc. Am. Bull., 103, 1121-1131, 1991.

Bishop, A. W.: The use of the slip circle in the stability analysis of slopes, Geotechnique, 5(1), 7-17, 1955.

Boukharov, G. N., Chanda, M. W., and Boukharov, M. W.: The three processes of brittle crystalline rock creep, Int. J. Rock Mech. Min., 32, 325-335, 1995.

Brunsden, D.: Some geomorphological considerations for the future development of landslide models, Geomorphology, 30, 1324, 1999.

Chu, J., Leroueil, S., and Leong, W. K.: Unstable behaviour of sand and its implication for slope stability, Can. Geotech. J., 40, 873885,2003

Comegna, L. and Picarelli, L.: The interplay between pore pressures and slope movements in fine-grained materials, in: Proceedings of the 11th International Conference of the International Association of Computer Methods and Advances in Geomechanics, Torino, Italy, 3, 497-504, 19-24 June 2005.

Dai, F. C., Lee, C. F., Wang, S. J., and Feng, Y. Y.: Stress-strain behaviour of loosely compacted volcanic-derived soil and its significance to rainfall-induced fill slope failures, Eng. Geol, 53(3-4), 359-370, 1999.

Eckersley, J. D.: Instrumented laboratory flowslides, Geotechnique, 40, 489-502, 1990.

Giusti, G., Iacarino, G., Pellegrino, A., Russo, C., Urcioli, G., and Picarelli, L.: Kinematic features of earthflows in Southern Apennines, Italy, in: Proceedings of the 7th International Symposium on Landslides, Trondheim, Norway, 1, 457-462, 17-21 June 1996.

Harp, E. W., Weels, W. G., and Sarmiento, J. G.: Pore pressure response during failure in soils, Geol. Soc. Am. Bull., 102(4), 428-438, 1990.

Helmstetter, A., Sornette, D., Grasso, J.-R., Andersen, J. V., Gluzman, S., and Pisarenko, V.: Slider-block friction model for landslides: implication for prediction of mountain collapse, J. Geophys. Res., 109, B02409, doi:10.1029/2002JB002160, 2004.

Ishihara, K.: Liquefaction and flow failure during earthquakes, Geotechnique, 47(3), 349-451, 1993.
Iverson, R. M., Reid, M. E., Iverson, N. R., LaHusen, R. G., Logan, M., Mann, J. E., and Brien, D. L.: Acute sensitivity of landslide rates to initial soil porosity, Science, 290, 513-516, 2000.

Iverson, M., Reid, M. E., and LaHusen, R. G.: Debris flow mobilization from landslides, Annu. Rev. Earth Pl. Sc., 25, 85-138, 1997.

Keefer, D. K. and Johnson, A. M.: Earth flow morphology, mobilization and movement, Geol. Surv. Prof. Paper, 1264, 56 pp., 1983.

Kilburn, C. R. J. and Petley, D. N.: Forecasting giant, catastrophic slope collapse: lessons from Vajont, northern Italy, Geomorphology, 54(1-2), 21-32, 2003.

Klubertanz, G., Laloui, L., and Vulliet, L.: On the use of multiphase modelling to simulate the initiation of slope movements, in: Proceedings of the 8th International Symposium on Landslides, Cardiff, UK, 2, 831-836, 26-30 June 2000.

Malet, J.-P.: Les "glissements de type écoulement" dans les marnes noires des Alpes du Sud. Morphologie, fonctionnement et modélisation hydro-mécanique, Ph.D. thesis, University Louis Pasteur, Strasbourg, France, 394 pp., 2003.

Malet, J.-P., Laigle, D., Remaître, A., and Maquaire, O.: Triggering conditions of debris-flows associated to complex earthflows The case of the Super-Sauze earthflow (South Alps, France), Geomorphology, 66(1-4), 215-235, 2005.

Maquaire, O., Malet, J.-P., Remaître, A., Locat, J., Klotz, S., and Guillon, J.: Instability conditions of marly hillslopes: towards landsliding or gullying? The case of the Barcelonnette Basin, South East France, Eng. Geol., 70(1-2), 109-130, 2003.

Nieuwenhuis, J. D.: The lifetime of a landslide, Balkema, Rotterdam, Netherlands, 1991.

Petley, D. N., Bulmer, M. H., and Murphy, W.: Patterns of movement in rotational and translational landslides, Geology, 30, 719722, 2002.

Picarelli, L., Russo, C., and Urcioli, G.: Modelling earthflow movement based on experiences, in: Proceedings of the 11th European Conference on Soil Mechanics and Foundation Engineering, Copenhagen, Danemark, 11-15 June 2007, 6, 157-162, 1995.

Picarelli, L., Urciuoli, G., Ramondini, M., and Comegna, L.: Main features of mudslides in tectonised highly fissured clay shales, Landslides, 2, 15-30, 2005.

Sassa, K.: Mechanisms of landslide triggered debris flow, in: Environmental Forest Science, Kluwer, Dordrecht, Netherlands, 471490, 1988.

Smith, G. N. and Smith, I. G. N.: Elements of Soil Mechanics, Blackwell Science, Oxford, UK, 1998.

van Asch, T. W. J., Malet, J.-P., and van Beek, L. P. H.: Influence of landslide geometry and kinematic deformation to describe the liquefaction of landslides: some theoretical considerations, Eng. Geol., 88(1-2), 59-69, 2006.

van Genuchten, P. M. B.: Movement mechanisms and slide velocity variations of landslides in varved clays in the French Alps, Ph.D. thesis, Utrecht University, Netherlands, 160 pp., 1989.

Wang, G. and Sassa, K.: Pore pressure generation and movement of rainfall-induced landslides: effect of grain size and fine particle content, Eng. Geol., 69, 109-125, 2003.

Whitlow, R.: Basic Soil Mechanics, Longman Scientific \& Technical, Harlow, UK, 1995. 